\title{
Planning of Recreation Parks in the University Campus
}

\author{
Anthopoulos K. Petros, George Costa
}

Democritus University of Thrace, Department of Physical Education and Sport Science, Komotini, Greece. Email: panthopo@phyed.duth.gr

Received February $20^{\text {th }}, 2011$; revised March $28^{\text {th }}, 2011$; accepted May $1^{\text {st }}, 2011$.

\begin{abstract}
The benefits of parks and recreation are very serious. The purpose of this study was to investigate the attitudes of the people that use the campus area of Democritus university of Thrace, in Komotini. There are series of factors that should be taken under consideration when campus is under planned. In this research took part 742 people and more specific, they were: under graduate students, post graduate students, tutors as well as teaching and administrative staff. An analysis of Principle components has been accomplished and 8 factors have been accrued with eigenvalue more than 1. These factors explain the $55.32 \%$ of the whole variation. The conclusion of this study was that a model for campus planning must consists of these 8 parameters: land, climate, vegetation, physical activity, environmental consciousness, daily users of territory and inhabitants of an area.
\end{abstract}

Keywords: Campus, Park, Physical Activity, Questionnaire

\section{Introduction}

Greek towns' public space is faced, from the majority of the citizens, as an unconcerned topic. It is not recognized as a common good which is not only available to them but also it isn't considered as an obligation to protect it. It is a totally strange thing to the citizens and for this reason it is often polluted or violated by them. The same behavior is noticed in the green urban space even if it is public or private. The public green outdoors is the victim of the rapid urbanization and super-construction which after $60 \mathrm{~s}$, possessing it was thought a luxury but often an unnecessary one. It is a topic superficially discussed in relation to the urban lay out, putting it in contrast to the practice done in the European and international space, in which green is the major keystone in the organization and function of the urban groups.

In the Greek society green public places are limited. They are not properly organized. Also, the option of the location and planting is badly selected. Green places happened accidentally according to the constructive density where the latter permits it. This doesn't enable their integration to the town's functionality.

Stress is a powerful factor of mortality [1] for the humans who live in modern societies or industrialized societies. This phenomenon results in two things: first, it does higher the cure cost and second, there are lost working hours. Psychological health is a sign of humans' good physical condition. U.K.D.H. [2] points that physical exercise helps people feel better improving at the same time their mood and limiting their worry. Exercise increases self respect and reduces stress reactions while managing a better quality of sleep.

Parks, passages and green places that exist in a town offer an active way of life prohibiting obesity and sudden deaths [3-6]. Natural activity benefits persons in their physical and psychological behavior [7]. When exercise is done inside the natural environment then an added factor comes on surface. A term known as green exercise is mentioned by Pretty and his colleagues. Environment must be kept intact for ethical and financial reasons [8-11]. Little attention has been given to the advantages of the psychic health. Less natural environment means bad human condition and stress higher percentage [12]. So, research results show that green contributes to the human health and helps to get over stress, while it boosts immune system. Also, it does concentration easier.

Universities' open space and tutoring quality are two contrastive things. The plan of a campus, the unity of the surroundings and the buildings help for a pleasant place not only for the students but also for the academic staff.

Institutions are usually situated in the center of a town. So their right planning is critical. There is an attempt for 
them to function as free spaces available and amusing to the people. An interaction as well as cooperation between the urban web and the outdoor space should be feasible. Neighborhood is the basic society's element. An institution must function as a neighborhood or as a system of neighborhoods that are accessible to the locals offering not only knowledge but also other important things. Natural elements and institutional characteristics indicate the mixture level with the constructive web of the town [13].

Aristotle university of Thessaloniki's campus is downtown (Figure 1). Some green places exist in the center of the campus but they are not designed and created rationally. There is a big surface which is covered with sod and a small number of trees in abnormal and accidental thesis. There is also a small pond but it is not reclaimed. Due to the length of the campuses' streets there are trees that offer protection from the various weather conditions. An important but negative effect is the creation of a square in front of the positive studies school and the medicine school. This square is paved without green. In addition, a huge concrete construction in front of the library that causes a bad impression. There is a satisfactory attempt around the philosophical, law and religious schools.

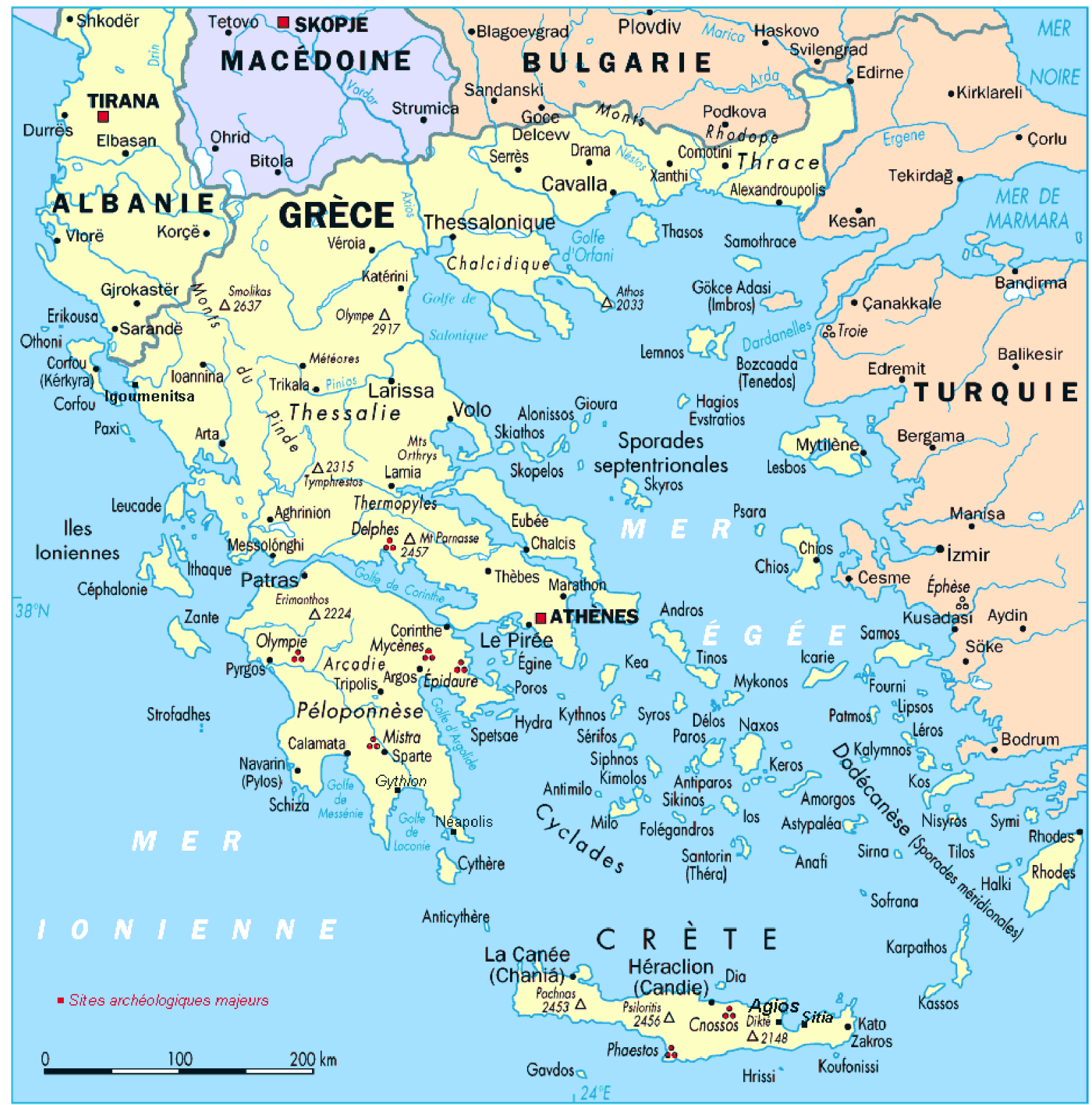

Map of Greece 


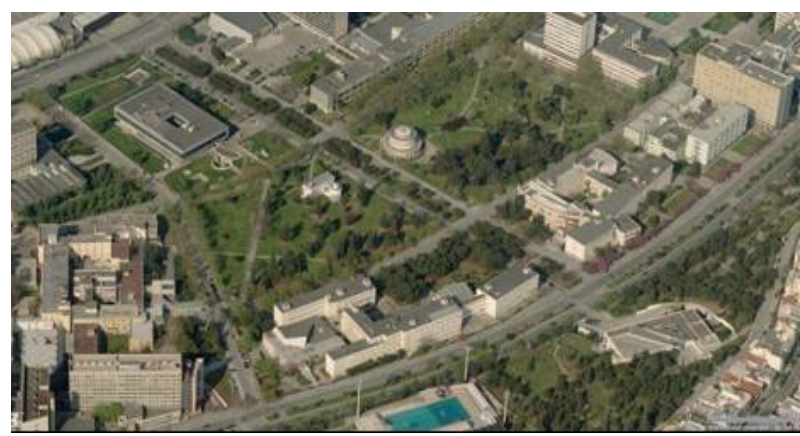

Figure 1. Aristotle University of Thessaloniki (Google).

The campus of Athens is in an area that called Zografou in the beginning of the mountain Immetus (Figure 2). Observing this field we can find self sown vegetation and especially the kind of pine cones. There aren't any other green places but there are many sports facilities. Cars are exposed to the weather because the protection in the parking lacks. Around the buildings there is vegetation roughly designed.

Patras campus (Figure 3) is a better example for planning and configuring the outwards. There are important interventions to the surroundings that make things positive. There are voluminous buildings not inappropriately placed because of the physical function of the area. There is a vehicle protection in park station accompanied by the presence of vegetation. We can find additional places without green or creating shadow. A positive thing is the existence of sculpture, almost in every building, that is eye catching. Furthermore, there is sod and some trees. A negative element is the water intensive sod. In Patras campus some desultory squares and some buildings are

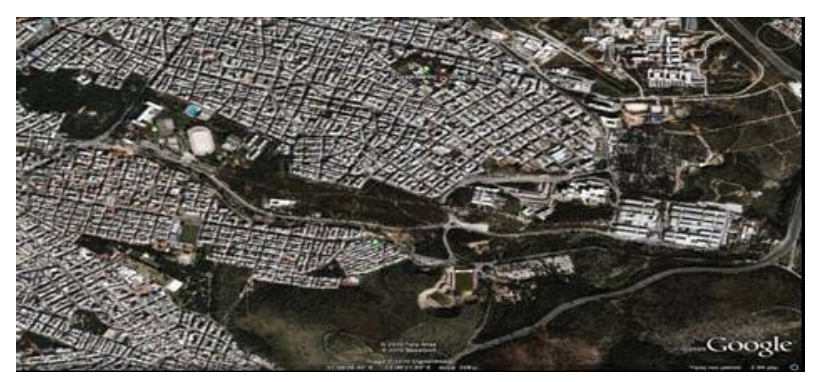

Figure 2. The campus of Athens (Google).

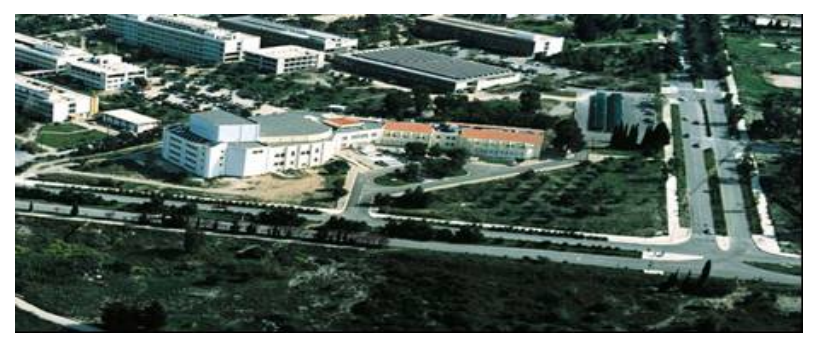

Figure 3. Patras campus (Google). obvious. Finally, there are some sport facilities available for the users.

The campus of Ioannina (Figure 4) covers a certain land away from the town's web. There are no traces of external design. The campus lacks in intervention in its majority. Instead, there are plain cases that are impressive. Also, some parking stations have deciduous trees for solar radiation protection during summer.

The agronomic university of Athens (Figure 5) is the web of the town. It is a good example in reference to the design and the configuration because of the landscape and the architecture laboratory. There are places for privacy, quiet, and rest, categorized in the whole length of the campus. A negative thing is the presence of chairs made by concrete, which is not compatible with the environment. The most pedestrian precincts are configured rightly with some kinds of palm trees that are compatible with the climate. Parking stations are characterized from vegetation and they are weather protected. There is some vegetation as for example some fences that are useful to separate the space. Finally, there are eye catching items, not always as successful as a palm trees.

\section{Method}

\subsection{Questionnaire}

The draft of a questionnaire by professional scientists of physical education and landscape's architecture became real. It was distributed to a number of people to the

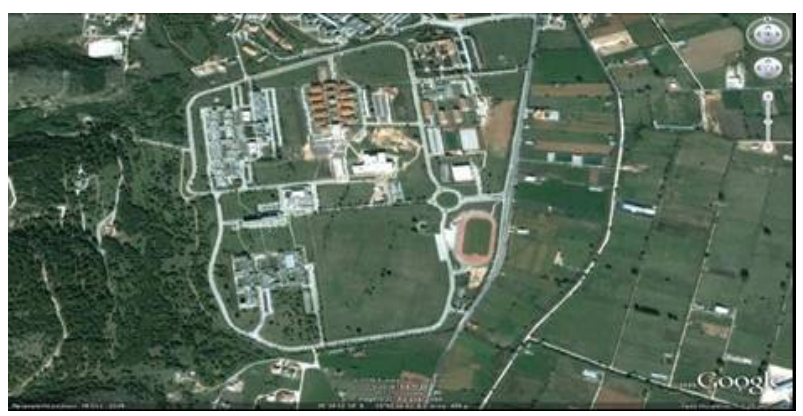

Figure 4. The campus of Ioannina (Google).

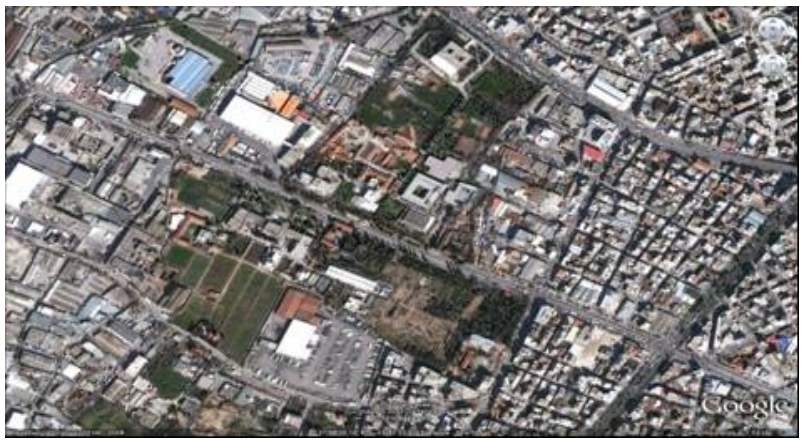

Figure 5. The agronomic university of Athens (Google). 
University of Komotini (Figure 6). Then it became a statistical treatment and its validity was checked by the Cronbach criterion.

This specific questionnaire has got closed quarries in order to be immediate filled. The responses were immediate from the users of the Komotini's campus. The process was done by a computer with the method of spss 17. In detail, as far as the form of the questionnaire it is the following. The first five questions have to do personal information such as age, sex, specification, family condition and semester. The rest 36 questions having a seventh degree-Likert climax (I totally agree $=1$, I certainly agree $=2$, I agree $=3$, I don't know $=4$, I disagree $=5$, I certainly disagree $=6$, I totally disagree $=7$ ) and were categorized in 6 groups: a) physical conditions, b) vegetation, c) activity, d) surrounding construction, e) users, f) environmental conscience.

\subsection{Participants}

The majority of the questioned people aged less than 25 years old because of their student identity. $60.6 \%$ were women and 39.4\%were men. The most of them were not married. In D.U.TH. (Democritus University of Thrace) of Komotini the data are: educational personnel $5.7 \%$, administrative staff $4.6 \%$, under graduate students $75.5 \%$ and post graduate students $14.3 \%$. The research was set in D.U.TH. in March 2010 with stratificated sampling. The total population was sub divided in homogenous and uncovered sub populating fields, based on users' specification.

The groups are a) tutoring personnel, b) administrative staff, c) undergraduate students, d) post graduate students. The participants were 742 in their total number. They are categorized proportionally to their specification and according to their university department.

\subsection{Statistical Analysis}

There is a principal components analysis in order to trace them and determine the kind of the 36 questions. Their validity was checked by a co efficient "a" created by Cronbach for each one of the results separately.

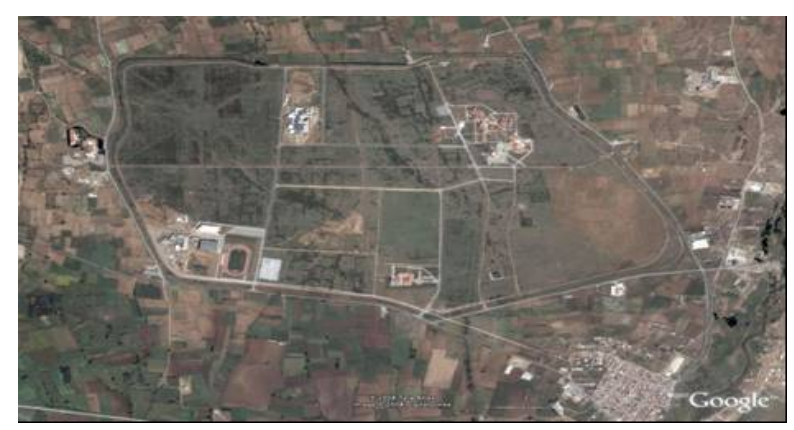

Figure 6. Democritus University of Thrace (Google).

\section{Results}

There is a principle component analysis to research the form of the 36 questions. The criterion for the eigenvalues exceeds 1 .

The diagnosis of the appropriateness in order to apply the principles in the under discussion data K.M.O. and Bartlett's test of sphericity give satisfactory results (K.M.O. $=0.862, x^{2}=8639.878, \mathrm{p}<0.01$ ). As an acceptable limit of loading in order to include a component in a summarized climax it was estimated the 0.40 .8 factors were selected after the research. They have value bigger than 1 that interpret the $55.32 \%$ of the whole scale because of the high interrelation between the factors there are results after varimax (Table 1). The cases are infrastructure, land, activity, climate, environmental consciousness, users, inhabitants.

As for the first factor $\mathrm{a}=0.784$, for the second $\mathrm{a}=$ 0.789 , for the third $\mathrm{a}=0.704$, for the fourth $\mathrm{a}=0.794$, for the fifth $\mathrm{a}=0.761$, for the seventh $\mathrm{a}=0.711$. These values show a little relation between the variables that create these elements. For the sixth factor the value is up to $\mathrm{a}=$ 0.662 and about the eighth the value is a $=0.675$. Finally, for the whole components the value is $a=0.644$ which shows that there is a strong relation between them.

\section{Discussion}

The existence and the application of the specific parameters during the design of the outdoors are necessary. The decision of the right factors is pivotal to the rational design. In the past, many researchers have referred the fact of the natural environment but without mingled with a questionnaire process. This survey is ambitious for covering this lack by forming the institutions externally. If we adapt this tool it is possible to use it to other similar institutions such as hospitals.

The present survey is the beginning of a questionnaire's growth that has its primary goal to form the spaces of the educational institutions. The results that accrued from the factors analysis were encouraging. The factors that finally occurred agree with other professional scientists' issues. They have proved in various researches the importance of the individual factor. Specifically, Dafis [14], supports that during the outdoor design should think about the physical conditions and should be used adaptable forestry and eco items. Dober [15] centers on the importance of these outdoor spaces that enable users necessities. Pretty [16] proves that exercise in a pleasant natural environment benefits blood pressure in contrast with the exercise in an artificial landscape which lacks in vegetation.

\section{Conclusions}

The survey comes to the conclusion that the users of 
Table 1. Principle component analysis.

\begin{tabular}{|c|c|c|c|c|c|c|c|c|}
\hline & \multicolumn{8}{|c|}{ Factors } \\
\hline & 1 & 2 & 3 & 4 & 5 & 6 & 7 & 8 \\
\hline Subject focus & 0.679 & & & & & & & \\
\hline Botanical garden & 0.649 & & & & & & & \\
\hline Cultural & 0.593 & & & & & & & \\
\hline Fences plants & 0.570 & & & & & & & \\
\hline Environmental information & 0.556 & & & & & & & \\
\hline Meeting spaces & 0.554 & & & & & & & \\
\hline View locations & 0.551 & & & & & & & \\
\hline Isolation sights & 0.513 & & & & & & & \\
\hline Type of soil & & 0.723 & & & & & & \\
\hline Soil depth & & 0.664 & & & & & & \\
\hline Terrain & & 0.577 & & & & & & \\
\hline Soil moisture & & 0.572 & & & & & & \\
\hline Slope land & & 0.531 & & & & & & \\
\hline Moderate activity & & & 0.676 & & & & & \\
\hline Alternative forms of activity & & & 0.646 & & & & & \\
\hline Extreme sports & & & 0.621 & & & & & \\
\hline Team sports & & & 0.612 & & & & & \\
\hline Sports spaces & & & 0.572 & & & & & \\
\hline Footpaths & & & 0.546 & & & & & \\
\hline Rainfall & & & & 0.794 & & & & \\
\hline Wind & & & & 0.723 & & & & \\
\hline Humidity & & & & 0.640 & & & & \\
\hline Trees shape & & & & & 0.783 & & & \\
\hline Trees colors & & & & & 0.728 & & & \\
\hline Trees height & & & & & 0.573 & & & \\
\hline Trees type & & & & & 0.503 & & & \\
\hline Roads & & & & & & 0.733 & & \\
\hline Car using & & & & & & 0.693 & & \\
\hline Close buildings & & & & & & 0.661 & & \\
\hline Materials of construction & & & & & & 0.657 & & \\
\hline Opinion users & & & & & & & 0.815 & \\
\hline Wishes users & & & & & & & 0.795 & \\
\hline Active participation users & & & & & & & 0.480 & \\
\hline Access inhabitants & & & & & & & & 0.802 \\
\hline Active participation inhabitants & & & & & & & & 0.731 \\
\hline Events & & & & & & & & 0.703 \\
\hline
\end{tabular}

Extraction method: principal component analysis. Rotation method: varimax with kaiser normalization. 
the campus of Komotini find critical the 8 factors of Principle component analysis. So, they believe that the designer of such a place should consider the land (soil, topography etc.) and the climate (rain, wind etc.) of the reason, the existed and not vegetation, the construction that may use the visitors, the environmental factors (materials, botanic garden, information about environment), the sub assistance of physical activity (fields, adventure park etc.) and the views of users (students, professors) and the citizens who live around the campus. Finally, the scientist who wants to plan a university campus has a tool which could follow. We think that he model which came from this study and it consists of the above 8 parameters is useful for environmentalists and help the protection of physical environment.

\section{REFERENCES}

[1] L. Rainford, V. Mason, M. Hickman and A. Morgan, "Health in England 1998. Investigating the Links between Social Inequalities and Health,” The Stationery Office, London, 2000.

[2] United Kingdom Department of Health, “At Least Five a Week: Evidence on the Impact of Physical Activity and Its Relationship to Health,” A Report from the Chief Medical Officer, London, 2004.

[3] L. D. Frank and P. O. Engelke, "The Built Environment and Human Activity Patterns: Exploring The Impacts Of Urban Form On Public Health,” Journal of Planning Literature, Vol. 16, No. 2, 2001, pp. 202-218. doi:10.1177/08854120122093339

[4] C. Maller, et al., "Healthy Nature Healthy People, 'Contact with Nature' as an Upstream Health Promotion Intervention for Populations," Health Promotion International, Vol. 21, No. 1, 2005, pp. 45-54.

[5] S. E. Coen and N. Ross, "Exploring the Material Basis for Health: Characteristics Of Parks In Montreal Neighbourhoods With Contrasting Health Outcomes," Health and
Place, Vol. 12, No. 4, 2006, pp. 361-371. doi:10.1016/j.healthplace.2005.02.001

[6] K. Reynolds, J. Wolch, J. Byrne, C. Chou, G. Feng, S. Weaver and M. Jerrett, "Trail Characteristics as Correlates of Urban Trail Use," American Journal of Health Promotion, Vol. 21, No. 4, 2007, pp. 335-345.

[7] D. Scully, J. Kremer, M. Meade, R. Graham and K. Dudgeon, "Physical Exercise and Psychological Wellbeing: A Critical Review,” British Journal Sports Science, Vol. 32, No. 2, 1999, pp. 11-20.

[8] A. Leopold, “A Sand County Almanac and Sketches Here and There,” Oxford University Press, Oxford, 1949.

[9] Costanza, et al., "The Value of the World's Ecosystem Services and Natural Capital,” Nature, Vol. 387, 1997, pp. 253-260. doi:10.1038/387253a0

[10] R. Eckersley, "The Discourse Ethic and the Problem of Representing Nature,” Environmental Politics, Vol. 8, No 2, 1999, pp. 24-49.

[11] P. A. Sandifer, A. F. Holland, T. K. Rowles and G. I. Scott, "The Oceans and Human Health," Environmental Health Perspective, Vol. 112, No. 8, 2004, pp. 454-455. doi:10.1289/Ehp.112-A454

[12] J. Pretty, M. Griffin and M. Sellens, "Is Nature Good for You?,” Ecosystem, Vol. 24, 2004, pp. 2-9.

[13] P. Anthopoulos and J. Georgi, "Research Employer's Preferences for Landscape Design of Grounds and Spaces Surrounding Hospitals. Case Study University Hospital of Alexandroupolis," Congress of Landscape Architecture \& Urban Environment, Drama, 12-17 April, 2010.

[14] S. Dafis, "Urban Forestry, Art of Text," Thessaloniki, Greece, 2001.

[15] R. Dober, "Campus Landscape: Functions, Forms, Features,” John Wiley \& Sons, New York, 2000.

[16] J. Pretty, "How Nature Contributes to Mental and Physical Health," Spirituality \& Health International, Vol. 5, No 2, 2004, pp. 68-78. doi:10.1002/shi.220 